\title{
The Digital Audio Broadcasting Journey from the Lab to Listeners - the Czech Republic Case Study
}

\author{
Karel ZYKA \\ Czech Radio, Vinohradská 12, 12099 Praha 2, Czech Republic \\ karel.zyka@rozhlas.cz \\ Submitted February 14, 2019 / Accepted April 19, 2019
}

\begin{abstract}
This paper describes the complex experiences and the results of the Digital Audio Broadcasting (DAB+) implementation in the conditions of the Czech Republic. It analyses the background of the EUREKA 147 program, its targets, and to what extent they were reached. The main focus is concentrated on the evaluation of the real steps which had to be done during the implementation process before the first regular broadcasting could be started and the difficulties encountered. The key point became experimental broadcasting "DAB Prague". It demonstrated the advantages of this new platform and gave the opportunity to test its functions and physical behavior in real conditions, under the different parameter settings. The important issue is the allocation of the band III by the National Regulatory Authority and the capacity of $D A B+$ multiplexes. The paper also demonstrates the experience from the setup of the $D A B+$ headend. It describes the content solution in context of using non-entropic audio coding, setting the codec algorithms and the way to use accompanying multimedia services. The results of the tests and measurements presented in this paper were used in the real project of the regular nationwide $D A B+$ network.
\end{abstract}

\section{Keywords}

DAB+, Digital Audio Broadcasting, EUREKA 147, multiplex, headend, non-entropic audio coding

\section{Introduction}

Digital Audio Broadcasting $(\mathrm{DAB}+)$ represents one of the modern forms of terrestrial radio broadcasting [1], [2]. It is a complex of technological innovations developed in the late 1980s as a part of the European Commission's investment program Eureka 147 [3], [4], supporting the competitiveness of European industry. The aim was to develop a more efficient broadcasting system for audio, text and visual content distribution to fixed, portable and mobile receivers. The system should have provided listeners with a high quality of audio, separate transmission capacity for additional data and enable a mobile reception even at higher speeds, while keeping receivers easy to use.
It should also have ensured a more efficient use of the frequency spectrum and required lower power of transmitters. The new broadcasting system was developed in Europe at a time when there were no private stations in this part of the world. Its basic characteristics are thus better suited to the operation of large national territories, where it is more effective than spot coverage of individual cities and smaller areas. In February 1995, Digital Audio Broadcasting (DAB) was defined by the European Telecommunications Standards Institute (ETSI) in the standard ETSI EN 300401 [2]. The Norwegian public service broadcaster NRK, the first in the world, began broadcasting on 1 June 1995 in the DAB system via the NRK Klassisk.

In addition to the audio channel, the data channel is also transmitted in the DAB. This can contain additional information or applications. The most important ones are: Dynamic Label (DL), which is a short text message about broadcasted content; Slideshow (SLS), which is a series of images broadcasted as a carousel; Service and Program Information (SPI), which is the DAB / DAB + alternative to a similar service (Electronic Program Guide), used in the DVB-T / DVB-T2 (Digital Video Broadcasting -Terrestrial) television system [5], [6] and Transport Protocol Experts Group (TMC/TPEG), which brings extended traffic and travel information and services to drivers.

An improved version called $\mathrm{DAB}+[1]$ was introduced in February 2007. DAB+ is more efficient thanks to the use of a new audio codec (HE-AACv2 instead of MP2) and more robust thanks to the use of additional Reed-Solomon error correction coding. $\mathrm{DAB}+$ is only backward compatible with DAB, not vice versa.

In Europe, $\mathrm{DAB}+$ has become a new standard for radio. Some countries have already replaced an analogue broadcasting by the system DAB+ (Norway, 2017) or are planning to do so soon (Switzerland, Denmark). In most European countries, the $\mathrm{DAB}+$ is developing as a new parallel distribution platform. The Czech Republic is one of the active states representing the emerging markets category. On the other hand, there are also some countries in Europe that do not yet support DAB+ (e.g. Finland) or still evaluate it (e.g. Sweden).

In this paper, an overview of the $\mathrm{DAB}+$ implementation in the Czech Republic is given. The paper is organized 
in the following manner. In Sec. 2, the key principles of the $\mathrm{DAB} / \mathrm{DAB}+$ are emphasized. Section 3 describes the experimental $\mathrm{DAB}+$ broadcasting in the Czech Republic. The results of the field measurement are presented in Sec. 4. In Sec. 5 , the way of the $\mathrm{DAB}+$ headend configuration is explained, with the focus on the audio content. Section 6 describes the start of the regular DAB + broadcasting in the Czech Republic followed by Sec. 7, which focuses on the band III allocation. Section 8 presents the conclusion gained during this process.

\section{Key Innovations Used in DAB / DAB+}

\subsection{Lossy Digital Audio Compression}

For audio coding, DAB employs MPEG-1 Audio Layer 2, also known as MP2 or MPEG 2 (Moving Picture Experts Group) [7]. This is based on the earlier MUSICAM codec (Masking pattern adapted Universal Subband Integrated Coding and Multiplexing) that was invented by the German Institut für Rundfunktechnik (IRT) even before the Eureka 147 consortium was established. The bit rate is reduced by a psychoacoustic coding of the signal in the time domain using the sub-band filter bank. MPEG 2 allows compression of digital audio signal in a wide range from $8 \mathrm{kbps}$ to $384 \mathrm{kbps}$ at a sampling frequency of $48 \mathrm{kHz}$ or $24 \mathrm{kHz}$. Using bit rate $192 \mathrm{kbps}$ or higher, a high-quality sound of stereo signal can be achieved that is comparable, by subjective perception, to so called "CD quality".

In the upgraded version, $\mathrm{DAB}+$, from 2007 [8], [9], the original Audio Codec MPEG-1 Audio Layer 2 is replaced by a new, significantly more effective coding called AAC (Advanced Audio Coding) [9], [10], [11]. AAC belongs to a family of so-called transform codecs operating in the frequency domain using some type of time-frequency domain transformation (modified discrete cosine transform (MDCT), Fast Fourier transform (FFT) or other). Its basic form (Core Codec), referred to as AAC LC (Low Complexity), is complemented by two superstructures, SBR and PS. Depending on the level of their use, we talk about HEAAC (High Efficiency) version 1 (v1) or version 2 (v2). The first superstructure is Spectral Band Replication (SBR), invented by Coding Technologies AB in 2001. The second superstructure is Parametric Stereo (PS) [12]. When using SBR, the core codec operates only at a half of the sampling frequency. Higher frequencies are encoded by the SBR superstructure and the full bandwidth is reconstructed only in the receiver decoder. In the HE-AACv2 mode both superstructures (SBR+PS) are engaged together with core codec, but only the sum signal of the left and right channels $(\mathrm{M}=\mathrm{L}+\mathrm{R})$ is encoded by core codec and SBR. The difference signal $\mathrm{S}$ is then encoded separately by Parametric Stereo. In addition to the reconstruction of higher frequencies, particular stereo channel signals $(\mathrm{L}=\mathrm{M}-\mathrm{S}$,
$\mathrm{R}=\mathrm{M}+\mathrm{S}$ ) are also calculated in the receiver decoder. The total HE-AAC bit rate is then made up by the core codec bit rate and by the contributions of both superstructures. Both superstructure codecs contribute to the total bit rate only in the range of units of kbps. The final coding efficiency is then up to four times higher compared with the older codec MPEG-1 Audio Layer 2.

\subsection{Transmission Coding \& Multiplexing}

The audio and supplementary data of all services must be combined together - multiplexed into one common bitstream, referred to as a DAB multiplex (DAB ensemble).

The DAB system uses the convolutional channel coding FEC (Forward Error Correction), which is optimized to suppress transmission errors. When coding, it adds redundant protection bits to the data bits.

While the original version of DAB used punctured convolutional coding (some of the bits of the protection code are omitted from the transmission), the upgraded $\mathrm{DAB}+$ keeps the original convolutional encoder, but it adds additional Reed-Solomon code, resulting in concatenated coding. The additional protective codec is independent for each service in the multiplex and the FEC protection level can be set individually for each program. There are five levels of FEC protection ratios (1A, 2A, 3A, 3B, $4 \mathrm{~A})$ where number one provides the highest level of protection and number four the lowest. The higher the protection level, the lower the receiver's demands are on the intensity of the electromagnetic field for error-free reproduction of the received signal. At the same time, this decreases the useful capacity of the multiplex.

\subsection{COFDM Modulation and the Single Frequency Networks (SFN)}

The new modulation method COFDM [13] was also invented prior to the start of the Eureka 147 project, by the research institute of France Telecom and the TDF (CCETT). The so-called Coded Orthogonal FrequencyDivision Multiplexing or COFDM uses multiple carrier modulation. In the case of $\mathrm{DAB} / \mathrm{DAB}+$, Differential Quadrature Phase Shift Keying (DQPSK) modulation is used on 1536 carrier frequencies, spacing in $1 \mathrm{kHz}$, forming a total multiplex bandwidth of $1.536 \mathrm{MHz}$. The data of the multiplex are then distributed by all carrier frequencies. This method allows a significant reduction of symbol rate for each carrier and brings higher protection against interference between direct and reflected signals at the input of the receiver. By inserting guard intervals into the transmitter signal, the signal becomes practically insensitive to multipath interferences whose delay is less than the length of the guard interval. If the reflected signal delay is shorter than the guard interval, signals are constructively combined, improving reception. This COFDM property allows for the creation of synchronous networks, referred to as a single frequency networks (SFN) which significantly 
improves the effective use of the frequency spectrum, compared to previous analog systems, e.g. FM.

\section{Start of the DAB+ in the Czech Republic}

In 2015, Czech Radio, the national public service broadcaster, introduced its long-term concept of digital audio broadcasting development. In the so-called "Seven Steps to Digital Broadcasting", it proposed the necessary measures in technology and legislation. The concept deals with issues of national coordination, technology \& rollout, funding, involvement of private broadcasters, attractive content and new services, information campaigns and penetration of receivers. A national specialized conference was held in cooperation with the Academy of Performing Arts in Prague (HAMU).

\subsection{Experiment "DAB Prague"}

On August 6, 2015, Czech Radio, in cooperation with the network operator České Radiokomunikace (CRA) and supported by the National Regulatory Authority (CTO), launched the experimental (and also the first full-featured) broadcasting of the $\mathrm{DAB}+$ multiplex, referred to as "DAB Prague" [14]. The signal was accessible in the capital city of Prague and in part of Central Bohemia, covering 17\% of the population of the Czech Republic. Due to the lack of legislation, this method was the only way to demonstrate to the public the real broadcasting of the $\mathrm{DAB}+$ system. Using the main Prague transmitter (Žižkov tower), with radiated power of $20 \mathrm{~kW}$ ERP (transmitter power $4 \mathrm{~kW}$ ), the transmission had all of the parameters of full operation. The authorization of the CTO was issued for the band III and radio frequency block $12 \mathrm{C}(227.360 \mathrm{MHz})$ with vertical polarization of the antenna system. The multiplex included 14 Czech Radio stations, whose audio was encoded by the HE-AAC encoder and accompanied by multimedia data. In December 2016 a second transmitter in Beroun ( $30 \mathrm{~km}$ southwest of Prague) with $300 \mathrm{~W}$ ERP was added. This formed the SFN network, where basic parameters of network setup and synchronous operation were tested.

The "DAB Prague" experiment, which lasted for almost two years, has made $\mathrm{DAB}+$ broadcasting available for broad public to test all its features in real-life traffic. A number of measurements and verification tests of the physical behavior of the signal propagation have been carried out, especially in dense urban environments. The knowledge and experience gained from this experiment helped later to effectively plan, design and implement a regular broadcasting network. "DAB Prague" became a key activity that Czech Radio realized in connection with the preparation of regular broadcasting. The "DAB Prague" project de facto started the process of the radio digitalization in the Czech Republic.

\section{Measurements and Verification Tests}

As a part of the experimental broadcasting, the following measurements and verification tests were carried out:

- Practical verification of the coverage and reception of the signal compared to the prediction calculated by numerical modeling.

- Operational verification of the headend configurations.

- Optimization of audio encoding algorithms and different bitrates for various types of audio content.

- Testing of the influence of lossy audio coding, primary source quality, and concatenation of audio codecs, on the subjective perception of the sound quality.

- Testing the implementation of additional data services.

- Verification of reception quality on the road network with different settings of FEC robustness for individual stations.

- Optimization of the single frequency network (SFN) operation.

\subsection{Measurement of the FEC Protection Level Influence on the Useful Coverage of the DAB+ Transmitter}

In October 2015, CRA together with Czech Radio carried out the measurements to verify the real coverage of the $\mathrm{DAB}+$ signal transmitted from the Prague - City locality in band III, radio frequency block $12 \mathrm{C}$ (20 kW ERP, vertical polarization). The tests were carried out for each FEC protection level (1A / 2A / 3A / 4A) for particular services contained in the multiplex. The measurements were made at 158 points on eight azimuthal rays (N, NE, E, SE, S, SW, W and NW), centered around the Prague-City transmitter site. A field measurement vehicle was equipped with a spectrum analyzer FSQ8 (R\&S), a TV/R analyzer ETL (R\&S), a calibrated laboratory-grade radio receiver Sefram 7876, a logarithmic-periodic antenna HL223 (R\&S), a GPS receiver SveeSix Trimble, a car DAB+ receiver Blaupunkt Stockholm 230 DAB and a magnetic carantenna Hama DAB 107229. At each of the individual points the intensity of the electromagnetic field was measured at a height of $10 \mathrm{~m}$ above the terrain. The individual services contained in the tested $\mathrm{DAB}+$ multiplex, having different FEC protection levels, were further assessed in terms of reception quality by subjective listening via the car $\mathrm{DAB}+$ receiver, to which a standard car kit antenna was attached to the windshield of the car. 


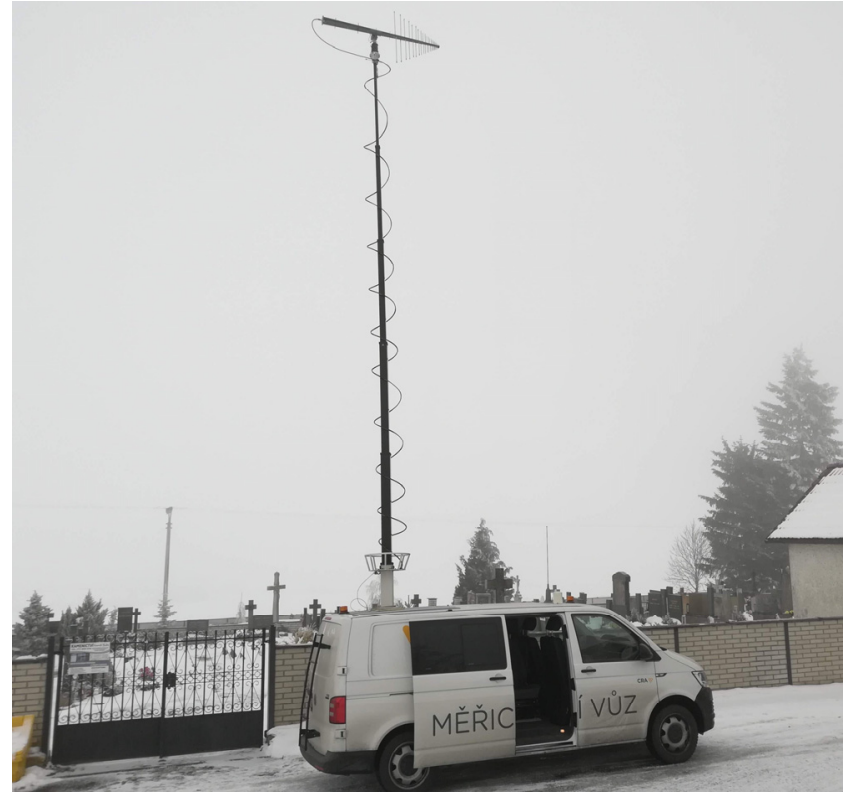

Fig. 1. Photograph of the field measurement vehicle used.

The results obtained in better secured modes (1A, 2A) show the signal on the NE and NW rays can be (due to the favorable nature of the terrain) received practically up to the borders of the Czech Republic. The measured values also allowed identifying the minimum intensity of the electromagnetic field necessary to achieve high quality reception of $\mathrm{DAB}+$ signal (i.e. the reception with subjectively unrecognizable impairments of sound quality) for each particular FEC protection level. According to CTO regulation No. 22/2011 [15], the intensity of the electromagnetic field required to receive the $\mathrm{DAB}+$ signal is $58 \mathrm{~dB} \mu \mathrm{V} / \mathrm{m}$. This corresponds to the measured values for protection level FEC 3A, which is referred to as "reference". For "Indoor and portable" coverage intensity of $66 \mathrm{~dB} \mu \mathrm{V} / \mathrm{m}$ is required. According to experience from Germany, increased electromagnetic field intensity to $76 \mathrm{~dB} \mu \mathrm{V} / \mathrm{m}$ is recommended for large urban agglomerations. As shown in Tab. 1, the values found for each particular FEC protection level (1A, 2A, 3A, 4A) correspond well to all values required by the CTO regulation [15]. Values of $1 \mathrm{~dB} \mu \mathrm{V} / \mathrm{m}$ lower than required (and in the case of FEC $2 \mathrm{~A}$ even $3.5 \mathrm{~dB} \mu \mathrm{V} / \mathrm{m}$ lower) were found sufficient.

\subsection{Measurement of the Real Coverage Area of "DAB Prague" and Comparison with the Numerical Model Prediction}

During April and May 2016, CTO in cooperation with CRA and Czech Radio carried out the measurements of the real coverage of the Prague - City transmitter. The transmitter was operating in the band III, radio frequency block 12C (227.360 MHz), with $20 \mathrm{~kW}$ ERP, FEC 2A protection level, and vertical polarization of the antenna system. Subsequently, a comparison with predicted coverage calculated by numerical modeling according to the ITU-R Recommendation P.1546-2 (International Tele-

\begin{tabular}{|c|c|c|c|}
\hline $\begin{array}{c}\text { Protection } \\
\text { level FEC }\end{array}$ & $\begin{array}{c}\text { Measured } \\
\text { values }\end{array}$ & $\begin{array}{c}\mathbf{E}_{\text {min }} \text { values by } \\
\text { the regulation } \\
\text { No. 22/2011 }\end{array}$ & $\begin{array}{c}\text { Difference in } \\
\text { measured and } \\
\text { regulation values }\end{array}$ \\
\hline FEC 1A & $51 \mathrm{~dB} \mu \mathrm{V} / \mathrm{m}$ & $52 \mathrm{~dB} \mu \mathrm{V} / \mathrm{m}$ & $-1 \mathrm{~dB} \mu \mathrm{V} / \mathrm{m}$ \\
\hline FEC 2A & $52 \mathrm{~dB} \mu \mathrm{V} / \mathrm{m}$ & $55.5 \mathrm{~dB} \mu \mathrm{V} / \mathrm{m}$ & $-3.5 \mathrm{~dB} \mu \mathrm{V} / \mathrm{m}$ \\
\hline FEC 3A & $57 \mathrm{~dB} \mu \mathrm{V} / \mathrm{m}$ & $58 \mathrm{~dB} \mu \mathrm{V} / \mathrm{m}$ & $-1 \mathrm{~dB} \mu \mathrm{V} / \mathrm{m}$ \\
\hline FEC 4A & $61 \mathrm{~dB} \mu \mathrm{V} / \mathrm{m}$ & $62 \mathrm{~dB} \mu \mathrm{V} / \mathrm{m}$ & $-1 \mathrm{~dB} \mu \mathrm{V} / \mathrm{m}$ \\
\hline
\end{tabular}

Tab. 1. Minimal Intensity of the electromagnetic field for subjectively unimpaired reception.

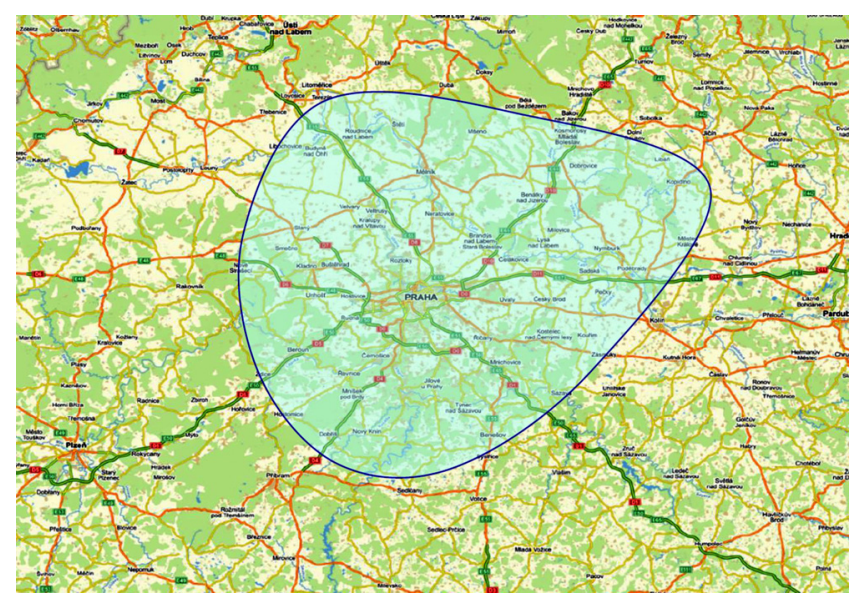

Fig. 2. The real measured coverage of "DAB Prague" transmitter (for $58 \mathrm{~dB} \mu \mathrm{V} / \mathrm{m}$ ).

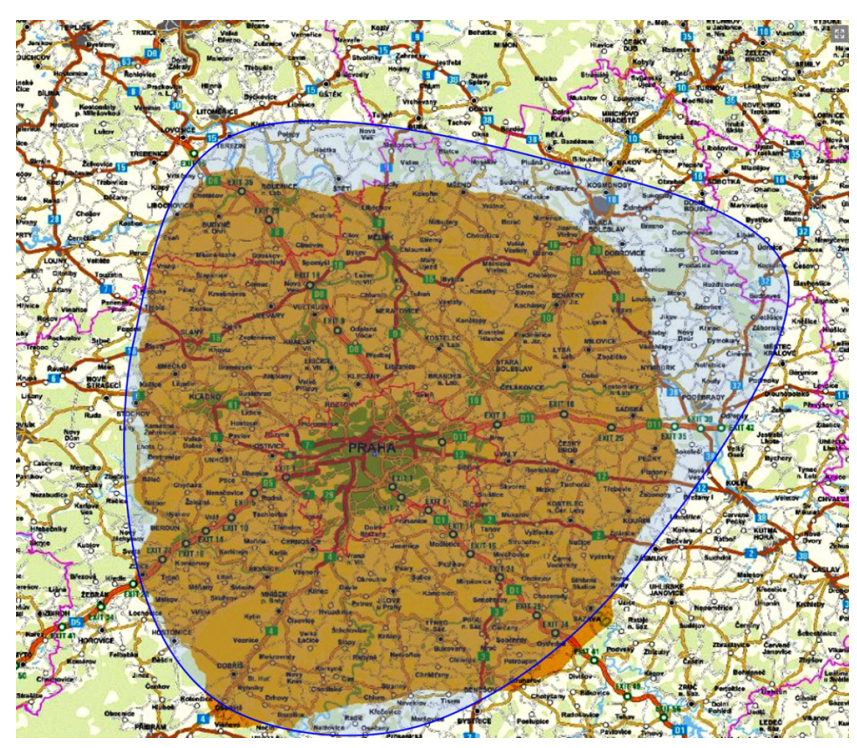

Fig. 3. The comparison of measured and predicted coverage (according to ITU for $58 \mathrm{~dB} \mu \mathrm{V} / \mathrm{m}$ ).

communication Union - Radiocommunication Sector) for the frequency band 174-230 MHz, was made [16].

The signal was measured on eight rays (azimuths) rotated by $45^{\circ}$, beginning with the azimuth $22.5^{\circ}$. When measuring the intensity of the electromagnetic field, the vertical profile of intensity was measured at each measuring point using two heights of the antenna (10 $\mathrm{m}$ and $4 \mathrm{~m}$ above the earth) to check signal homogeneity. The same field measurement vehicle was used as described in Sec. 4.1. 
From the analysis of measured data results (as shown in Figs. 2, 3) the real coverage is in good conformity with the predicted coverage. The visualization on the map shows that the real coverage in the north and northeast direction is even better than the modeled assumption.

\section{DAB + Headend Configuration}

The public service multiplex operated by Czech Radio includes 14 radio channels (audio services). The first group consists of nationwide radio stations, which are also accessible in analog FM networks (Radiožurnál, Dvojka, Vltava, Plus). The second group consists of selected regional radio stations (Brno, Ostrava, Pilsen, Regina, Region). The third group consists of special radio stations of Czech Radio, which are only accessible digitally (Radio Wave, Radio Junior, D-dur, Jazz, Radio Retro). All audio services are broadcasted in a stereo mode.

The key point when configuring the $\mathrm{DAB}+$ headend (see Tab. 2.) is the appropriate choice and setting of the audio encoding. The goal was to ensure efficient operation while keeping a high subjectively perceived sound quality [17], [18]. The assumptions were verified by blind listening tests. These were carried out in May 2015 in the main recording studio of Czech Radio "R1" (mixing console Studer Vista 9, digital audio workstation ProTools 10, audio monitors Genelec 1038). The listening panel was made up of evaluating subjects selected according to recommendation of ITU-R BS.1534-3 (MUSHRA) [19]. The group consisted of twenty experienced listeners who have experience with listening to sound in a critical way and with detecting small impairments of audio. The listening panel was structured as follows: 14 men and 6 women, age between 21 and 59 years, with an average age of 37 years. Before the blind test itself, the subjects were instructed on the form and content of the test, including the kind of impairments they should detect, which was the influence of lossy audio coding compared with non-processed reference. The critical audio material that was tested represents a typical broadcast program. Ten musical samples of various genres (rock, pop, classic, electronic, jazz, and singing) and types (dynamic, sound density) were used. Each sample was processed in these seven modifications (impairments): unprocessed original sound from a radio library (WAV 24 bit / $48 \mathrm{kHz}$ ), AAC LC with bitrate of $128 \mathrm{kbps}$, HE-AACv1 with bitrate of $96 \mathrm{kbps}$ and $80 \mathrm{kbps}$, HE-AACv2 with bitrate of $64 \mathrm{kbps}$ and $48 \mathrm{kbps}$ and MPEG2 with bitrate of $256 \mathrm{kbps}$.

A result of these blind listening tests is that the influence of the bitrate size alone on the subjective perception of sound quality is not dominant in relation to other parameters and signal characteristics. The dominant influence mainly has the primary sound quality at the input of transmission chain and the concatenation of lossy compression algorithms used in the individual technological phases (primary source, radio music library, distribution, $\mathrm{DAB}^{+}$

\begin{tabular}{|c|c|c|c|c|c|}
\hline Services & $\begin{array}{l}\text { Audio } \\
\text { coder }\end{array}$ & $\begin{array}{l}\text { Super- } \\
\text { structure }\end{array}$ & $\begin{array}{l}\text { Bitrate } \\
{[\mathrm{kbps}]}\end{array}$ & Mode & FEC \\
\hline \multicolumn{6}{|c|}{ nationwide radio stations } \\
\hline RADIOZURNAL & THE-AACv1 & $\overline{\mathrm{AAC} / \mathrm{SBR}}$ & 80 & Stereo & $2 \mathrm{~A}$ \\
\hline DVOJKA & HE-AACv1 & $\mathrm{AAC} / \mathrm{SBR}$ & 80 & Stereo & $2 \mathrm{~A}$ \\
\hline VLTAVA & HE-AACv1 & AAC/SBR & 80 & Stereo & $2 \mathrm{~A}$ \\
\hline PLUS & HE-AACv2 & $\mathrm{AAC} / \mathrm{SBR} / \mathrm{PS}$ & 48 & Stereo & $2 \mathrm{~A}$ \\
\hline \multicolumn{6}{|c|}{ regional radio stations } \\
\hline REGINA DAB & HE-AACv2 & $\mathrm{AAC} / \mathrm{SBR} / \mathrm{PS}$ & 48 & Stereo & $2 \mathrm{~A}$ \\
\hline REGION & HE-AACv2 & $\mathrm{AAC} / \mathrm{SBR} / \mathrm{PS}$ & 48 & Stereo & $2 \mathrm{~A}$ \\
\hline BRNO & HE-AACv2 & $\mathrm{AAC} / \mathrm{SBR} / \mathrm{PS}$ & 48 & Stereo & $2 \mathrm{~A}$ \\
\hline OSTRAVA & HE-AACv2 & $\mathrm{AAC} / \mathrm{SBR} / \mathrm{PS}$ & 48 & Stereo & $2 \mathrm{~A}$ \\
\hline PLZEN & HE-AACv2 & $\mathrm{AAC} / \mathrm{SBR} / \mathrm{PS}$ & 48 & Stereo & $2 \mathrm{~A}$ \\
\hline \multicolumn{6}{|c|}{ special radio stations } \\
\hline WAVE & HE-AACv1 & $\mathrm{AAC} / \mathrm{SBR}$ & 80 & Stereo & $2 \mathrm{~A}$ \\
\hline JUNIOR & HE-AACv2 & $\mathrm{AAC} / \mathrm{SBR} / \mathrm{PS}$ & 48 & Stereo & $2 \mathrm{~A}$ \\
\hline DDUR & HE-AACv1 & AAC/SBR & 80 & Stereo & $2 \mathrm{~A}$ \\
\hline JAZZ & HE-AACv1 & $\mathrm{AAC} / \mathrm{SBR}$ & 80 & Stereo & $2 \mathrm{~A}$ \\
\hline RETRO & HE-AACv2 & $\mathrm{AAC} / \mathrm{SBR} / \mathrm{PS}$ & 48 & Stereo & $2 \mathrm{~A}$ \\
\hline
\end{tabular}

Tab. 2. The headend configuration of Czech Radio DAB + multiplex.

transmitter). A statistically significant group of subjects $(65 \%)$ assessed the highest sound quality at the sample processed by encoding HE-AACv1 with bitrate of $80 \mathrm{kbps}$. The second best evaluated sample was coded by HEAACv2 codec with bitrate of $48 \mathrm{kbps}$. Based on the results of these blind tests, the algorithm HE-AACv1 (with SBR) and HE-AACv2 (with both SBR and PS superstructures) were selected to encode the audio programs in the $\mathrm{DAB}+$ multiplex of Czech Radio. The codec HE-AACv1 with bitrate of $80 \mathrm{kbps}$ was used for the coding of all audio programs with a higher share of music and HE-AACv2 with bitrate of $48 \mathrm{kbps}$ for the coding of the programs with higher share of speech (regional broadcasting, talk formats etc.). In the case of Czech Radio, the entire signal path from the broadcasting studio to the audio encoder is completely lossless in the AES3 (AES / EBU) protocol. This eliminates any necessary transcoding between non-entropic audio codecs [20]. If the same audio program is broadcasted simultaneously in the analogue (FM) and digital $(\mathrm{DAB}+)$ platform, it is important to ensure separate audio processing by separated processors with appropriate configurations [21], [22]. Such a solution allows independent optimization for both platforms.

All services in the DAB+ multiplex have the same protection level setting of FEC 2A. This increases the area coverage of a transmitter compared to reference FEC $3 \mathrm{~A}$ at the same radiated power, to almost double the area. This is essential especially in the initial phase of the network deployment when it is desirable to achieve maximum coverage from a small number of transmitters.

In addition to the audio, Czech Radio provides the service of accompanying multimedia for each of its $\mathrm{DAB}^{+}$ stations. Each radio station provides the Dynamic Label in the form of text information about the currently broadcasted program or track. It also provides the Slide Show in the form of a carousel with a series of illustrative visuali- 
zations that are dynamically displayed in connection with a broadcasted program. There are other multimedia services in the development of Czech Radio that will offer new added value: visual weather forecast, visual traffic announcements, real-time view to the studio, display of the cover art of a currently-played song, and the connection of $\mathrm{DAB}+$ with the internet via RadioDNS service or QR code.

\section{Start of the Regular DAB+ Broadcasting}

The "DAB Prague" project is inspiring on an international level. Because of this project, in August 2016, the Ministry of Culture and the Government of the Czech Republic issued Resolution No.730, which allowed for the experiment to be terminated and to switch to regular broadcasting. From a critical point of view, this document unfortunately represents a missed opportunity for the Czech Republic. The positive change is that the $\mathrm{DAB}+$ can now be broadcasted on a regular basis. The regular broadcasting can be promoted and communicated to the public and the service level agreement (SLA) with the network operator can be signed. On the other hand, only one multiplex is allowed, despite the fact that the Czech Republic at that time already had frequencies for three nationwide multiplexes and that the interest of potential operators was clearly indicated. Moreover, the authorization for the regular broadcasting is limited only until the end of 2021 when the next steps are to be evaluated. The resolution of the Czech government de facto represents the postponement of a long-term national strategy of digital radio broadcasting for at least five years, i.e. until 2021. It congeals the current state without the possibility of significant development of the $\mathrm{DAB}+$ platform itself as well as the related fields. Such congealment also has a negative impact on frequencies. They cannot be internationally coordinated due to this fact, and the activity of neighboring countries reduces their future value in terms of the networks operation efficiency. This, unfortunately, leads to irreversible damage of national natural resources.

On June 1, 2017, Czech Radio launched the first regular broadcasting of DAB + in the Czech Republic. This was preceded by a legal analysis, the authorization of CTO, and signing of the contracts with technology partner CRA. The first step was to change the legal status of the current transmitter Prague - City (previously used in the experiment). On November 30, 2017, another three high-power $\mathrm{DAB}+$ transmitters were launched in urban agglomerations of the Czech Republic. The transmitter Prague - City was followed by transmitter Brno - Hády in the block 12D (229.072 MHz) with $5 \mathrm{~kW}$ ERP, transmitter Ostrava Hoštálkovice in the block $12 \mathrm{D}$ with $10 \mathrm{~kW}$ ERP and transmitter Pilsen - Radeč in the block $12 \mathrm{C}$ with $10 \mathrm{~kW}$ ERP. There is also the transmitter Beroun - Děd in the block $12 \mathrm{C}$ with $300 \mathrm{~W}$ ERP, which was originally used for setting and testing the synchronous SFN network during the experiment. It is now used to increase the homogeneity of the electromagnetic field on the D5 highway between the Prague and Pilsen transmitters. At the end of 2017, the coverage of the Czech Radio DAB + multiplex reached $40.8 \%$ of the Czech Republic population.

\section{The Allocation of Band III and the Capacity of the DAB+ Multiplexes}

The DAB system is generally capable of operating at frequencies from $30 \mathrm{MHz}$ to $3 \mathrm{GHz}$. A terrestrial DAB (T-DAB) operates in the band III (174-240 MHz) and also in L-band (1452-1490 MHz). In 2017, the DAB 2.1.1 specification unified its use only into the band III. Some countries (e.g. Poland, Finland), however, cannot follow this unification as the band III is already used for digital television DVB-T.

The DAB in the Czech Republic faced a similar problem in the past. At first, the band III was used for analog television. It was then split between DVB-T and $\mathrm{DAB}$, and $\mathrm{DAB}$ gained four channels that have made up three nationwide DAB multiplexes. Two of them can be divided into smaller geographical areas for use of regional broadcasting. One of them can be divided into only two parts (Bohemia and Moravia). This is the one that is operated by public service Czech Radio. On February 15, 2018, CTO issued a "Radio Spectrum Utilization Plan" [23] and decided that the whole band III will be allocated to the Digital Audio Broadcasting Service - Terrestrial DAB as shown in Tab. 3. It means that another 4 to 5 nationwide DAB multiplexes can now be assembled. As a result, the Czech Republic can now operate up to 8 nationwide DAB multiplexes, which indicates a great development potential.

For better consideration it is important to convert the potential in the multiplexes to real capacity in terms of the number of particular radio stations that can be contained in the $\mathrm{DAB}+$ platform. Using a high efficiency audio coding, one multiplex can contain about 20 radio stations. Considering a geographical division of the Czech Republic into 10 areas, and assuming that a half of the multiplexes will have nationwide coverage and a half will have regionalized coverage (separated into 10 areas), we thus get the usable capacity of Czech DAB multiplexes: a total number of 80 nationwide radio stations and 800 regional radio stations

\begin{tabular}{|l|c|c|c|c|}
\hline $\begin{array}{l}\text { Channel } \\
\text { and range }[\mathrm{MHz}]\end{array}$ & \multicolumn{2}{|c|}{$\begin{array}{c}\text { Band III } \\
\text { before Feb. 15, 2018 }\end{array}$} & \multicolumn{2}{c|}{$\begin{array}{c}\text { Band III } \\
\text { after Feb. 15, 2018 }\end{array}$} \\
\hline $\mathbf{5}(174-181)$ & & DAB & & DAB \\
\hline $\mathbf{6}(181-188)$ & DVB-T & & & DAB \\
\hline $\mathbf{7 ( 1 8 8 - 1 9 5 )}$ & DVB-T & & & DAB \\
\hline $\mathbf{8}(195-202)$ & DVB-T & & & DAB \\
\hline $\mathbf{9}(202-209)$ & DVB-T & & & DAB \\
\hline $\mathbf{1 0}(209-216)$ & & DAB & & DAB \\
\hline $\mathbf{1 1}(216-223)$ & & DAB & & DAB \\
\hline $\mathbf{1 2}(223-230)$ & & DAB & & DAB \\
\hline
\end{tabular}

Tab. 3. The development of the band III allocation in the Czech Republic. 
Usable number of radio stations in all Czech multiplexes

- the symbol of one nationwide radio station

- the symbol of one regional radio station

\begin{tabular}{|c|c|c|}
\hline MUX 1 & $\bullet \bullet \bullet \bullet \bullet \bullet \bullet \bullet \bullet \bullet \bullet \bullet \bullet \bullet \bullet \bullet \bullet \bullet \bullet \bullet$ & \multirow{4}{*}{$\begin{array}{c}\mathbf{8 0} \\
\text { nation- } \\
\text { wide } \\
\text { stations }\end{array}$} \\
\hline MUX 2 & 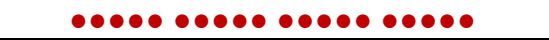 & \\
\hline MUX 3 & $\bullet \bullet \bullet \bullet \bullet \bullet \bullet \bullet \bullet \bullet \bullet \bullet \bullet \bullet \bullet \bullet \bullet \bullet \bullet \bullet$ & \\
\hline MUX 4 & $\bullet \bullet \bullet \bullet \bullet \bullet \bullet \bullet \bullet \bullet \bullet \bullet \bullet \bullet \bullet \bullet \bullet \bullet \bullet \bullet$ & \\
\hline MUX 5 & 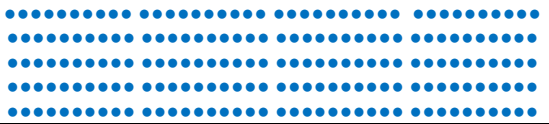 & \multirow{4}{*}{$\begin{array}{l}\mathbf{8 0 0} \\
\text { regional } \\
\text { stations }\end{array}$} \\
\hline MUX 6 & 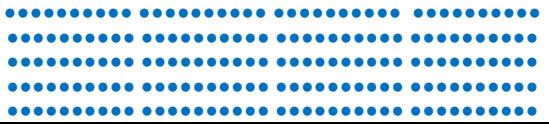 & \\
\hline MUX 7 & 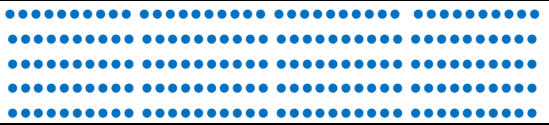 & \\
\hline MUX 8 & 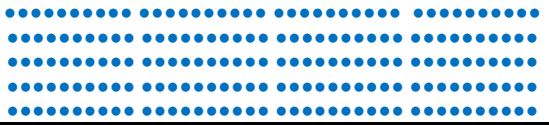 & \\
\hline
\end{tabular}

Tab. 4. Usable capacity of all potential DAB multiplexes in the Czech Republic.

(see Tab. 4.). This potential space is approximately ten times higher than the current capacity of analog (FM/AM) broadcasting.

\section{Conclusion}

The paper summarizes the results achieved in the process of planning, implementing and parameter verification of the first nationwide DAB+ network in the Czech Republic. It serves as the case study sharing the $\mathrm{DAB}+$ implementation experiences, results, and measurements with the research community.

From the measurement results of the high-power transmitter (Prague - City) coverage, depending on various protection levels FEC, it was found that for the FEC $3 \mathrm{~A}$ protection level the value of $57 \mathrm{~dB} \mu \mathrm{V} / \mathrm{m}$ represents a sufficient intensity of the electromagnetic field, compared to the value of $58 \mathrm{~dB} \mu \mathrm{V} / \mathrm{m}$ required by $\mathrm{CTO}$ regulation No. 22/2011. In the same direction are shifted the results for all FEC protection levels. The value measured for FEC $2 \mathrm{~A}$ is even lower. It is lower by $3.5 \mathrm{~dB} \mu \mathrm{V} / \mathrm{m}$ compared to the value derived from that CTO regulation. BER (Bit Error Rate) and MER (Modulation Error Ratio) values were also monitored during the field measurements. Subjectively undisturbed sound quality was achieved at BER values typically below $2.5 \mathrm{E}-5$ and MER typically above $26.5 \mathrm{~dB}$ for protection level FEC 2A. Measured results played a dominant role in the selection of the protection level of all services in the Czech Radio DAB + multiplex to the FEC 2A.

Blind listening tests have brought significant results of subjective perception of sound quality using low bitrates. Based on these tests, two audio codec configurations were chosen: HE-AAC-v1 with a bitrate of $80 \mathrm{kbps}$, and
HE-AAC-v2 with a bitrate of $48 \mathrm{kbps}$. These configurations fully respect the subjective perception of high sound quality while effectively using the data stream. The result is an optimal trade-off between the coverage, the multiplex capacity and the sound quality. This is especially important in the early stages of DAB + deployment, when we have to rely on a relatively small number of high-power transmitters. The result of the chosen concept is effective coverage combined with a high quality of sound and a sufficient number of broadcasted services

In the subsequent rollout of a nationwide $\mathrm{DAB}+$ network, the main focus will be on: optimizing radiated powers, geographical spacing of transmitters (primarily in regard to the guard interval), and optimizing network performance by adding additional transmitters. Further measurements and tests will be carried out focusing on the application of gap-fillers or separate low-power transmitters, especially with regard to the nature of the terrain.

\section{References}

[1] HOEG, W., LAUTERBACH, T. (Eds.) Digital Audio Broadcasting: Principles and Applications of DAB. DAB+ and $D M B .3^{\text {rd }}$ ed. John Wiley \& Sons, 2009. ISBN: 978-0-470-51037-7

[2] ETSI ETSI European Standard EN 300401 V2.1.1 Radio Broadcasting Systems; Digital Audio Broadcasting (DAB) to Mobile, Portable and Fixed Receivers, 01/2017.

[3] O' NEILL, B. DAB Eureka-147: The European platform for digital radio. New Media Society, 2009, vol. 11, no. 1-2, p. 261-278. DOI: $10.1177 / 1461444808099578$

[4] BOWER, A. J. BBC digital radio - The Eureka 147 DAB system. Electronic Engineering, April 1998, p. 55-56. [Online] Available at: http://downloads.bbc.co.uk/rd/pubs/reports/1998-10.pdf

[5] ETSI ETSI European Standard EN 302755 V1.4.1 Digital Video Broadcasting (DVB); Frame Structure Channel Coding and Modulation for a Second Generation Digital Terrestrial Television Broadcasting System (DVB-T2), 07/2015.

[6] WHITE PAPER PLANNING DVB-T2, Advance and Challenge. WHP01 3, LS telcom AG. October 2010. [Online] Available at: https://www.lstelcom.com/fileadmin/content/marketing/news/LS WhitePaper DVB-T2 en.pdf

[7] ETSI ETSI Technical Specification TS 103466 V1.1.1. Digital Audio Broadcasting (DAB); DAB Audio Coding (MPEG Layer II), $10 / 2016$.

[8] GILSKI, P. DAB vs DAB + radio broadcasting: A subjective comparative study. Archives of Acoustics, 2017, vol. 42, no. 4 p. 715-723. DOI: 10.1515/aoa-2017-0074

[9] BRANDENBURG, K. MP3 and AAC explained. In AES 17th International Conference on High Quality Audio Coding. Florence (Italy), 1999, p. 1-12.

[10] ETSI ETSI Technical Specification TS 102 563, Digital Audio Broadcasting (DAB); Transport of Advanced Audio Coding (AAC) Audio, Sophia Antipolis Cedex, France, 2010.

[11] HERRE, J., DIETZ, M. MPEG-4 high-efficiency AAC coding [Standards in a Nutshell]. IEEE Signal Processing Magazine, 2008, vol. 25, no. 3, p. 137-142. DOI: 10.1109/MSP.2008.918684

[12] ITU RADIOCOMMUNICATION SECTOR, GENEVA SWITZERLAND. Audio Coding for Digital Broadcasting. BS 
Series Broadcasting Service (Sound). Recommendation ITU-R BS.1196. 2001-2017. Approved in 2017-12.

[13] JAIN, P., SHARMA, S. Efficient performance analysis of OFDM based DAB systems using Reed Solomon coding technique. IOSR Journal of Electronics and Communication Engineering, 2015, vol. 10 , no. 4 , p. 56-59. DOI: 10.9790/2834-10435659

[14] NATIONAL REGULATORY AUTHORITY (CTO) Press Release about the Experimental Broadcasting "DAB Prague", 2015. [Online] Available at: https://www.ctu.cz/tiskova-zpravactu-podporil-experimentalni-vysilani-t-dab

[15] NATIONAL REGULATORY AUTHORITY (CTO) Regulation No. 22/2011 on the Method of Setting the Coverage of Terrestrial Radio Broadcasting in Selected Bands. 2011.

[16] ITU RADIOCOMMUNICATION SECTOR, GENEVA SWITZERLAND. Method for Point-to-Area Predictions for Terrestrial Services in the Frequency Range $30 \mathrm{MHz}$ to $3000 \mathrm{MHz}$. Recommendation ITU-R P.1546-2. Approved in 2013-09.

[17] ULOVEC, K., SMUTNY, M. Perceived audio quality analysis in digital audio broadcasting Plus system based on PEAQ. Radioengineering, 2018, vol. 27, no. 1, p. 342-352. DOI: $10.13164 /$ re.2018.0342

[18] GILSKI, P., STEFAŃSKI, J. Subjective and objective comparative study of DAB+ broadcast system. Archives of Acoustics, 2017, vol. 42, no. 1, p. 3-11. DOI: 10.1515/aoa-2017-0001

[19] ITU RADIOCOMMUNICATION SECTOR, GENEVA SWITZERLAND. Method for the Subjective Assessment of Intermediate Quality Levels of Coding Systems. Recommendation ITU-R BS.1534. 2001-2015. Approved in 2015-10.

[20] STRANAK, P. New methods of stereo encoding for FM radio broadcasting based on digital technology. Radioengineering, 2007, vol. 16 , no. 4 , p. 12-17. ISSN: 1210-2512
[21] BONELLO, O. Multiband audio processing and its influence on the coverage area of the FM stereo transmission. Journal of Audio Engineering Society, 2007, vol. 55, no. 3, p. 145-156.

[22] STRANAK, P. Interfering DC component, suppression and influence to digital signal processing. Radioengineering, 2008, vol. 17, no. 3, p. 121-123. ISSN: 1210-2512

[23] NATIONAL REGULATORY AUTHORITY (CTO) Part of the Radio Spectrum Utilisation Plan for the Frequency Band 174-380 MHz. No. PV-P/21/01.2018-2, 2018.

\section{About the Author ...}

Karel ZÝKA was born in Prague, the Czech Republic, in 1967. He received his M.Sc. from the Faculty of Electrical Engineering at the Czech Technical University in Prague in 1992. He is employed at Czech Radio, a national public service broadcaster, where he is the Technical Director and the head of the digital switchover team, which is implementing the $\mathrm{DAB}+$ in the Czech Republic. He is a member of WorldDAB and EDRA Steering Boards and works for the EBU. In the past, he was engaged at "Radio Alfa", implementing the first satellite distribution system in the Czech Republic, and at TV Prima, where he participated in the DVB-T transformation. Currently, he is an external postgraduate Ph.D. student at the Department of Sound Production at the Academy of Performing Arts in Prague (HAMU). 